\title{
Altered stoichiometry of an evolved RNA aptamer
}

\author{
SHOJI OHUCHI ${ }^{1}$ and BEATRIX SUESS \\ Department of Biology, Technische Universität Darmstadt, 64287 Darmstadt, Germany
}

\begin{abstract}
Inhibitory aptamers against a protein are promising as antagonistic reagents and repressive genetic components. Typically, improvement of such aptamers is achieved by acquiring higher binding affinity. Here, we report an alternative mechanism for the improvement of aptamer activity. Recently, we reported a transcriptional activator based on an inhibitory RNA aptamer against lambda cl repressor. We improved the aptamer through in vitro selection (SELEX) from a randomly mutagenized aptamer pool, followed by in vivo screening and truncation. Biochemical analyses indicated that the activity improvement was achieved by alteration of the complex formation stoichiometry, rather than by higher affinity or expression. Our results suggest an alternative strategy for improving aptamer activity.
\end{abstract}

Keywords: stoichiometry; aptamer; directed evolution; repressor

\section{INTRODUCTION}

Aptamers are artificial affinity oligonucleotides (DNA, RNA, and their derivatives) selected in vitro from a large population of random sequences based on their affinity to target molecules by a process known as SELEX (Systematic Evolution of Ligands by EXponential enrichment) (Ellington and Szostak 1990; Tuerk and Gold 1990; Joyce 2007; Ellington et al. 2009). Owing to their high affinities and specificities, as well as the ease of molecular engineering, various aptamer applications have been explored. Especially, their application as protein antagonists has been extensively studied, since aptamer against a protein often inhibits its activity (Parashar 2016; Tabarzad and Jafari 2016). Usually, the initial SELEX attempt identifies aptamers with nonoptimal antagonistic activity. Thus, increase in affinity via engineering of the original sequence (e.g., mutations and truncations) is required to improve aptamer activity.

Recently, we reported an artificial transcriptional activator based on an inhibitory RNA aptamer (aptamer D01, Fig. 1A) against a widely used repressor protein, lambda cI (Ohuchi and Suess 2017). The aptamer inhibits the binding of cI repressor to its corresponding operator DNA, inducing gene expression under repressor control. Here, we report directed evolution of this aptamer for higher transcriptional activation and an unexpected activity improvement mechanism, namely altered complex formation stoichiometry.

\footnotetext{
${ }^{1}$ Present address: Institute of Microbiology, Technische Universität Dresden, 01217 Dresden, Germany

Corresponding author: shojiohuchi@gmail.com

Article is online at http://www.rnajournal.org/cgi/doi/10.1261/rna 063610.117.
}

\section{RESULTS}

\section{Generation of a highly active aptamer variant}

To improve the in vivo transcriptional activator activity of the previously obtained RNA aptamer against lambda cI, aptamer D01 (Ohuchi and Suess 2017), we examined directed evolution of the aptamer (Fig. 1A). For this, a doped pool in which $15 \%$ of the aptamer sequence was randomly mutagenized $(85 \%$ of the original nucleotide and $3 \times 5 \%$ of all other nucleotides) was prepared. Since the deletion of $6 \mathrm{nu}-$ cleotides (nt) from the 3 -end did not affect activity (Ohuchi and Suess 2017), this region was omitted from the randomization. According to a blue-white colony color assay using a reporter plasmid on which LacZa expression is suppressed by cI repressor, a very low percentage of the population $(<0.3 \%)$ showed detectable activity in vivo (Supplemental Fig. 1A).

Thus, SELEX against hexa-histidine-tagged cI protein was performed to enrich the active variants in the pool before in vivo screening. After two rounds of SELEX, the pool RNA showed increased affinity to cI protein (Supplemental Fig. 1B). Thus, E. coli cells harboring the reporter plasmid were transformed with plasmids expressing RNA from the enriched pool. More than $80 \%$ of the transformants developed a clear blue color comparable to that of cells expressing the original aptamer, and the blue colonies were randomly chosen for sequencing. Although theoretically, only $0.003 \%$ of the population in the initial pool should have the original

(C) 2018 Ohuchi and Suess This article is distributed exclusively by the RNA Society for the first 12 months after the full-issue publication date (see http:// rnajournal.cshlp.org/site/misc/terms.xhtml). After 12 months, it is available under a Creative Commons License (Attribution-NonCommercial 4.0 International), as described at http://creativecommons.org/licenses/by-nc/4.0/. 
A

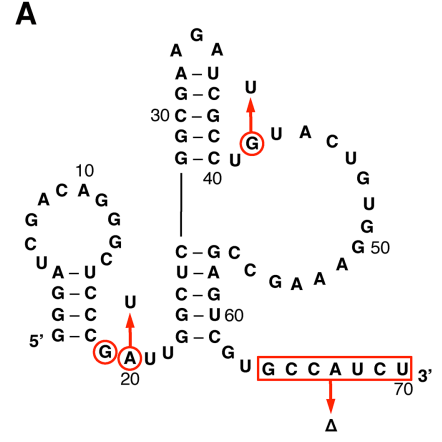

B

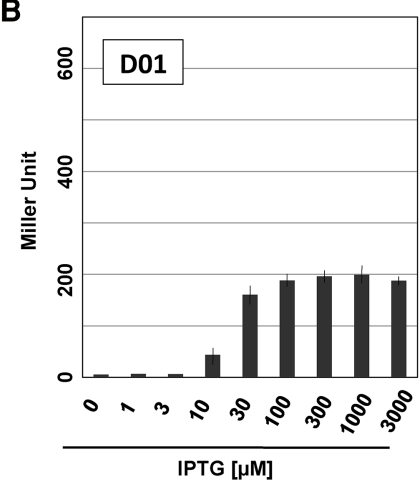

C

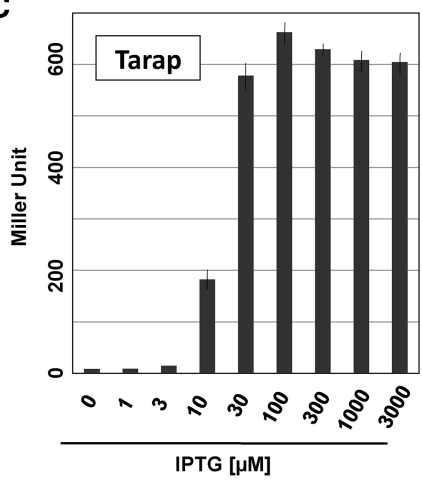

FIGURE 1. Original and evolved RNA aptamers with transcriptional activator activity. (A) Secondary structure of aptamer D01. Three mutational hot-spots and base-pairings are shown by red circles and thin lines, respectively. Red arrows indicate the mutations and truncation (represented as " $\Delta$ ") in aptamer Tarap. (B) Effect of induction level of aptamer D01 on the reporter expression. The aptamer was expressed under the control of a Tac promoter in E. coli DH5a cells harboring the reporter plasmid in which LacZ expression is suppressed by cI repressor. Cells were cultured in the presence of indicated IPTG concentrations and harvested at the late stationary phase. The activity of the reporter, $\beta$-galactosidase, was quantified by the Miller assay. At least, two independent assays were performed in duplicate for each two independent colonies, and the mean values are shown. Error bars indicate standard deviation. The data are from the previous report (Ohuchi and Suess 2017). (C) Effect of induction level of aptamer Tarap on the reporter expression. The assay was performed as described for $B$.

sequence, 18 colonies (35\%) out of 52 colonies possessed an RNA sequence identical to the original aptamer D01 sequence. This unusual enrichment of the original sequence can be explained by the results of previous mutational analyses, where most point mutations would rearrange the global secondary (2D) structure of the aptamer (Ohuchi and Suess 2017). The remaining 34 colonies carried at least one mutation, and among them, several mutations were frequently observed.

The frequent appearance of particular mutations suggests that these mutations are advantageous to activity. Thus, the in vivo transcriptional activator activities of the three most frequent mutations (G19U, A20U, and G47U), as well as combinations of these mutations, were quantitatively analyzed based on the aptamer D01 derivative with 6-nt truncation from the $3^{\prime}$-end [variant $\left.\operatorname{GAG}(0 /-6)\right]$ (Table 1). As expected, all these mutants showed improved activity, and the combination of A20U and G47U [variant Guu(0/-6)] showed the highest activity [2.6- and 2.4-fold higher than the original aptamer D01 and the parental variant $\mathrm{GAG}(0 /$ -6), respectively] (Table 1).

Further truncation of variant $\mathrm{Guu}(0 /-6)$ from the terminal ends was examined (Table 2). Truncations of up to 10nt from the 3 -end did not reduce activity, and further truncations were deleterious, as expected from the 2D structure of the aptamer (Fig. 1A). The 7-nt truncation [variant Guu(0/ -7)] showed further improvement of the activity [3.3- and 3.1-fold higher than the original aptamer D01 and the parental variant $\operatorname{GAG}(0 /-6)$, respectively]. Truncations from the $5^{\prime}$-end of this variant were then examined (Table 2). As expected from the $2 \mathrm{D}$ structure, in which the $5^{\prime}$-region is involved in stem formation, even 1-nt truncation reduced the activity, and further truncations abolished the detectable activity. The best variant $\mathrm{Guu}(0 /-7)$ was renamed as aptamer

TABLE 1. Effects of frequent mutations on transcriptional activator activity

\begin{tabular}{|c|c|c|}
\hline Variant & Sequence $\left(5^{\prime} \text {-to- } 3^{\prime}\right)^{\mathrm{a}}$ & $\begin{array}{l}\text { Miller } \\
\text { Unit }^{b}\end{array}$ \\
\hline D01 & $\begin{array}{l}\text { GGGAUCGACA GGGCUCCCGA UUGGCUCGGC GAAGAUCGCC UGUACUGUGG AAAGCCGAGU } \\
\text { CGUGCCAUCU }\end{array}$ & $199( \pm 18)$ \\
\hline GAG & GGGAUCGACA GGGCUCCCGA UUGGCUCGGC GAAGAUCGCC UGUACUGUGG AAAGCCGAGU CGUG & $213( \pm 12)$ \\
\hline $\mathrm{uAG}(0 /-6)$ & GGGAUCGACA GGGCUCCCUA UUGGCUCGGC GAAGAUCGCC UGUACUGUGG AAAGCCGAGU CGUG & $287( \pm 27)$ \\
\hline $\mathrm{GuG}(0 /-6)$ & GGGAUCGACA GGGCUCCCGU UUGGCUCGGC GAAGAUCGCC UGUACUGUGG AAAGCCGAGU CGUG & 343 \\
\hline $\mathrm{GAu}(0 /-6)$ & GGGAUCGACA GGGCUCCCGA UUGGCUCGGC GAAGAUCGCC UGUACUUUGG AAAGCCGAGU CGUG & 336 \\
\hline $\mathrm{uAu}(0 /-6)$ & GCUCGC & 333 \\
\hline $\mathrm{uuG}(0 /-6)$ & GGCUCCCUA UUGGCUCGGC GAAGAUCGCC UGU & $406( \pm 52)$ \\
\hline $\mathrm{Guu}(0 /-6)$ & GGGAUCGACA GGGCUCCCGU UUGGCUCGGC GAAGAUCGCC UGUACUUUGG AAAGCCGAGU CGUG & $514( \pm 15)$ \\
\hline $\mathrm{uuu}(0 /-6)$ & GGGAUCGACA GGGCUCCCUU UUGGCUCGGC GAAGAUCGCC UGUACUUUGG AAAGCCGAGU CGUG & $444( \pm 3)$ \\
\hline
\end{tabular}

${ }^{\mathrm{a}}$ Mutations are emphasized with red letters.

${ }^{b}$ Mean value of Miller Unit obtained by at least two independent assays performed in duplicate for each two independent colonies. 
TABLE 2. Effects of truncations on transcriptional activator activity

\begin{tabular}{|c|c|c|}
\hline Variant & Sequence $\left(5^{\prime} \text {-to- } 3^{\prime}\right)^{\mathrm{a}}$ & Miller Unit ${ }^{\mathrm{b}}$ \\
\hline $\mathrm{Guu}(0 /-6)$ & GGGAUCGACA GGGCUCCCGU UUGGCUCGGC GAAGAUCGCC UGUACUUUGG AAAGCCGAGU CGUG & $514( \pm 15)$ \\
\hline $\begin{array}{c}\text { Guu(0/-7) } \\
\text { (Tarap) }\end{array}$ & GGGAUCGACA GGGCUCCCGU UUGGCUCGGC GAAGAUCGCC UGUACUUUGG AAAGCCGAGU CGU & $666( \pm 21)$ \\
\hline $\mathrm{Guu}(0 /-8)$ & GGGAUCGACA GGGCUCCCGU UUGGCUCGGC GAAGAUCGCC UGUACUUUGG AAAGCCGAGU CG & $450( \pm 8)$ \\
\hline Guu(0/-9) & GGGAUCGACA GGGCUCCCGU UUGGCUCGGC GAAGAUCGCC UGUACUUUGG AAAGCCGAGU C & $427( \pm 32)$ \\
\hline Guu $(0 /-10)$ & GGGAUCGACA GGGCUCCCGU UUGGCUCGGC GAAGAUCGCC UGUACUUUGG AAAGCCGAGU & $531( \pm 34)$ \\
\hline $\operatorname{Guu}(0 /-11)$ & GGGAUCGACA GGGCUCCCGU UUGGCUCGGC GAAGAUCGCC UGUACUUUGG AAAGCCGAG & $328( \pm 14)$ \\
\hline $\operatorname{Guu}(0 /-12)$ & GGGAUCGACA GGGCUCCCGU UUGGCUCGGC GAAGAUCGCC UGUACUUUGG AAAGCCGA & $16( \pm 3)$ \\
\hline $\operatorname{Guu}(0 /-14)$ & GGGAUCGACA GGGCUCCCGU UUGGCUCGGC GAAGAUCGCC UGUACUUUGG AAAGCC & $1( \pm 0)$ \\
\hline Guu $(-1 /-7)$ & GGAUCGACA GGGCUCCCGU UUGGCUCGGC GAAGAUCGCC UGUACUUUGG AAAGCCGAGU CGU & $110( \pm 13)$ \\
\hline Guu $(-2 /-7)$ & GAUCGACA GGGCUCCCGU UUGGCUCGGC GAAGAUCGCC UGUACUUUGG AAAGCCGAGU CGU & $1( \pm 1)$ \\
\hline Guu $(-3 /-7)$ & AUCGACA GGGCUCCCGU UUGGCUCGGC GAAGAUCGCC UGUACUUUGG AAAGCCGAGU CGU & $1( \pm 0)$ \\
\hline
\end{tabular}

${ }^{\mathrm{a}}$ Mutations are emphasized with red letters.

${ }^{\mathrm{b}}$ Mean value of Miller Unit obtained by at least two independent assays performed in duplicate for each two independent colonies.

Tarap, standing for "Transcriptional activator based on an RNA aptamer" (Fig. $1 \bar{A})$.

To see the effect of induction level of aptamer Tarap expression on transcriptional activation, E. coli cells harboring the reporter plasmid and a Tarap-expression plasmid on which a Tac promoter directs the aptamer expression were grown in liquid media containing various concentrations of IPTG (Fig. 1C). As was the case for aptamer D01, transformation of the Tarap-expression plasmid increased the reporter expression even in the absence of IPTG, due to leaky expression (see below). The overall dependence on IPTG concentration for reporter expression in the Tarap-expressing cells was similar to that of the D01-expressing cells (Fig. 1B,C). Addition of $10 \mu \mathrm{M}$ IPTG increased the reporter elevation by 22 -fold, and $100 \mu \mathrm{M}$ increased it by 79-fold. However, IPTG concentrations higher than $300 \mu \mathrm{M}$ slightly reduced the elevation, and under these conditions, we observed the reduction of cell growth (Supplemental Fig. 2). This result suggests that high expression induction of aptamer Tarap is toxic for cells. The ON/OFF ratio of transcriptional activation of the Tarap-expressing cells (79-fold) is more than twofold higher than that of D01-expressing cells (35-fold), thereby representing an improved tool for controlling gene expression.

\section{Elucidation of activity improvement mechanism}

The improved activity of aptamer Tarap may result from an acquirement of higher affinity to cI protein, as previously reported for directed evolution of aptamers (Biesecker et al. 1999; Ohuchi et al. 2012; Duclair et al. 2015). Alternatively, the expression of aptamer Tarap may be higher than that of the original aptamer D01. To validate these hypotheses, we analyzed the affinity of aptamer Tarap by using a filter-retardation assay (Fig. 2A). Assuming the Hill coefficient of 1.0, aptamer Tarap showed a dissociation constant $\left(K_{\mathrm{d}}\right)$ of 518 $( \pm 96) \mathrm{nM}$ and a maximal percentage of the complex formation $\left(C_{\max }\right)$ of $55.6( \pm 9.9) \%$. These values are worse than those of aptamer D01 $\left(K_{\mathrm{d}}\right.$ of $273[ \pm 29] \mathrm{nM}$ and $C_{\max }$ of $58.2[ \pm 3.9] \%)$, indicating that improved affinity is not the reason for higher transcriptional activation. In contrast to the data for aptamer D01, the aptamer Tarap data does not match the binding curve for a Hill coefficient of 1.0 (the reduced $\chi^{2}$ value of 14.12), but does for a Hill coefficient of 2.0 (the $\chi^{2}$ value of 1.78). In this case, the $K_{\mathrm{d}}$ value $(264[ \pm 24] \mathrm{nM})$ is similar to that of aptamer D01, but the $C_{\max }$ value $(40.2[ \pm 5.2] \%)$ is worse. The previous analyses indicated that aptamer D01 tends to misfold at least in vitro, and low $C_{\max }$ values of the aptamers would be caused by misfolding (Ohuchi and Suess 2017).

Aptamer expression amounts were then analyzed by northern blotting to validate whether higher expression is implicated in improved activity (Fig. 2B,C). Cells expressing the aptamers under the control of a Tac promoter were grown at various concentrations of IPTG $(0,10,100$, or $1000 \mu \mathrm{M})$ to determine aptamer amounts under different induction levels. Total RNA extracted from these cells were subjected to northern blotting, using probes against the $5^{\prime}$ and $3^{\prime}$-regions of the aptamers. As expected from the results of the reporter assay (Fig. 1B,C), leaky expression of both aptamers was observed in the absence of IPTG. For both aptamers, addition of $10 \mu \mathrm{M}$ IPTG induced expression, 100 $\mu \mathrm{M}$ increased the expression three- to fourfold, and no further increase was observed in the presence of $1000 \mu \mathrm{M}$ IPTG. Surprisingly, the maximal expression amount of aptamer Tarap was similar to that of aptamer D01 (only 1.3-fold higher), indicating that higher expression is not the reason for improved transcriptional activation.

During analyses of the aptamers, we performed an electrophoretic mobility shift assay (EMSA) and found that degree of mobility shift upon binding to cI protein was larger for aptamer Tarap than for aptamer D01 (Fig. 3A). This result, together with the result of the binding assay (Fig. 2A), implied that stoichiometry of the aptamer Tarap-cI protein complex would differ from that of the aptamer D01-cI protein complex. 

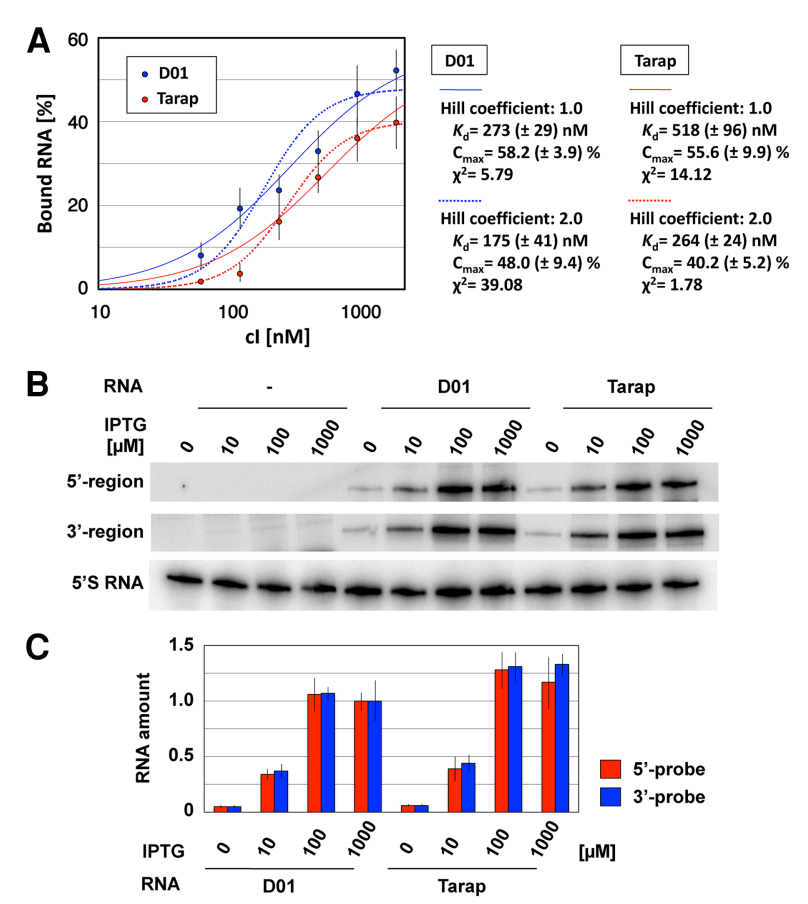

FIGURE 2. Evaluation of aptamer affinities and expression amounts. (A) Affinity of the aptamers to cI protein. Affinity was evaluated by a filter-retardation assay using $1 \mathrm{nM}$ of ${ }^{32} \mathrm{P}$-labeled RNA and the indicated concentrations of cI protein. The dissociation constant $\left(K_{\mathrm{d}}\right)$ and maximal percentage of complex formation $\left(C_{\max }\right)$ were estimated by curve fitting using Gnuplot 4.5.0. (gnuplot.sourceforge.net). Three independent assays were performed, and the mean values for aptamer D01 and aptamer Tarap are shown by blue and red dots, respectively. Error bars indicate standard deviation. The blue and red lines show the fitted curves for the data of aptamer D01 and aptamer Tarap, respectively. The solid lines are the curves for Hill coefficient of 1.0, whereas the dotted lines are for Hill coefficient of 2.0. " $\chi$ " indicates the reduced $\chi^{2}$ values for the curve fitting. The data for aptamer D01 are from the previous report (Ohuchi and Suess 2017). (B) Northern blot analysis of aptamer expression amounts. Using probes against the $5^{\prime}$-region (upper panel) or $3^{\prime}$-region (middle panel) of aptamers, the expression amounts were quantified. As a control, 5S RNA was also analyzed (lower panel). E. coli DH5a cells harboring the reporter plasmid and the RNAexpression plasmid (left four lanes, empty vector; middle four lanes, aptamer D01; right four lanes, aptamer Tarap) were cultured in the presence of indicated IPTG concentrations. The cells were harvested at the late stationary phase, and $2 \mu \mathrm{g}$ of RNA extracted from these cells was subjected to $8 \%$ denaturing PAGE, followed by northern blotting. $(C)$ Relative amount of the expressed aptamers. The band intensities of the aptamers in $B$ are normalized by the intensities of 5S RNA, and relative amount of the aptamers compared to the amount of aptamer D01 in the presence of $1 \mathrm{mM}$ IPTG are shown. Three independent assays were performed, and the mean values obtained with probes against $5^{\prime}$-region and $3^{\prime}$-region are shown by red and blue bars, respectively. Error bars indicate standard deviation.

To confirm this, titration analysis was performed by EMSA. The complex formation of a trace concentration of ${ }^{32} \mathrm{P}$-labeled aptamer was quantified in the presence of $1 \mu \mathrm{M}$ cI protein and various concentrations of unlabeled aptamer $(0-4 \mu \mathrm{M})$ (Fig. 3B,C). In the absence of unlabeled aptamer, $\sim 50 \%$ of both aptamers formed the complex with cI protein. Addition of 0.25 or $0.5 \mu \mathrm{M}$ of unlabeled aptamer slightly increased the complex formation. When more than $1 \mu \mathrm{M}$ of unlabeled aptamer was added, a titration effect was observed for both aptamers. Addition of 1,2, and $4 \mu \mathrm{M}$ of unlabeled aptamer D01 decreased labeled aptamer D01 complex formation by $17 \%, 52 \%$, and $73 \%$, respectively. ${ }^{2}$ As expected, aptamer Tarap showed a more drastic titration effect: Addition of 1,2, and $4 \mu \mathrm{M}$ decreased the complex formation by $44 \%, 81 \%$, and $91 \%$, respectively.

Finally, a similar EMSA analysis was performed for detecting cI protein complex formation. In this case, labeled aptamer was not used, and bands of cI protein were detected by western blotting (Fig. 3D,E). Compared to the band intensity of the complex ( $1 \mu \mathrm{M}$ cI protein) in the presence of $4 \mu \mathrm{M}$ RNA, the relative complex amounts in the presence of 0.5 and $1 \mu \mathrm{M}$ of aptamer D01 were $9 \%$ and $51 \%$, respectively. ${ }^{3}$ In contrast, the relative complex amounts in the presence of 0.5 and $1 \mu \mathrm{M}$ aptamer Tarap were $39 \%$ and $95 \%$, respectively, confirming higher complex formation efficiency with the evolved aptamer. As far as we know, this is the first report of directed evolution improving aptamer activity through altered stoichiometry.

\section{DISCUSSION}

In this study, we generated an evolved inhibitory RNA aptamer against cI repressor with transcriptional activator activity. The evolved aptamer Tarap showed more than threefold greater activity and more than a twofold greater $\mathrm{ON} /$ OFF ratio compared to the original aptamer D01. Surprisingly, aptamer Tarap showed similar affinity to cI protein and similar expression amounts compared to aptamer D01. Instead, results of the titration analyses indicated that aptamer Tarap has an altered complex formation stoichiometry with cI protein. Compared to the original aptamer D01, aptamer Tarap would prefer to bind to the functional dimer form of the protein. Thus, the activity improvement of aptamer Tarap would be achieved not only by the improved titration effect but also by this binding preference.

Until now, several inhibitory aptamers against DNAbinding proteins have been reported, typically possessing short sequences $(\sim 30 \mathrm{nt})$ and simple secondary structures (a single terminal or internal loop as a binding site). This is because such a structure is sufficient to bind to the DNA-binding pocket of the protein as demonstrated by the reported crystal structures of aptamer-protein complexes (Huang et al. 2003; Kettenberger et al. 2006; Miller et al. 2016). In contrast, the cI-binding RNA aptamers we isolated have longer sequences $(>60-n t)$ with a complex secondary structure (Fig. 1A). It is plausible that separate loops of such long aptamers would recognize not only a single region

\footnotetext{
${ }^{2}$ Aptamer D01 often produced two complex bands with cI protein whereas such band segregation was never observed for aptamer Tarap, supporting the difference of complex outcome involving these aptamers.

${ }^{3}$ Transfer of free cI protein onto the membrane was less efficient than that of complexed cI. Thus, it is impossible to judge the protein concentrations in the complex by comparing the band intensities of free protein and complexed protein.
} 
A

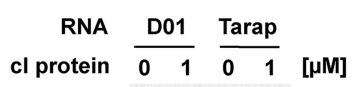

B

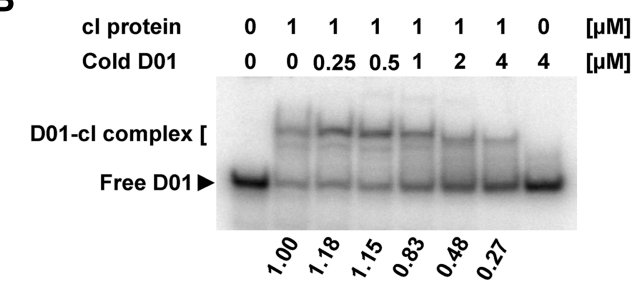

C

$\begin{array}{llllllllll}\text { cl protein } & 0 & 1 & 1 & 1 & 1 & 1 & 1 & 0 & {[\mu \mathrm{M}]}\end{array}$ $\begin{array}{llllllllll}\text { Cold Tarap } & 0 & 0 & 0.25 & 0.5 & 1 & 2 & 4 & 4 & {[\mu \mathrm{M}]}\end{array}$
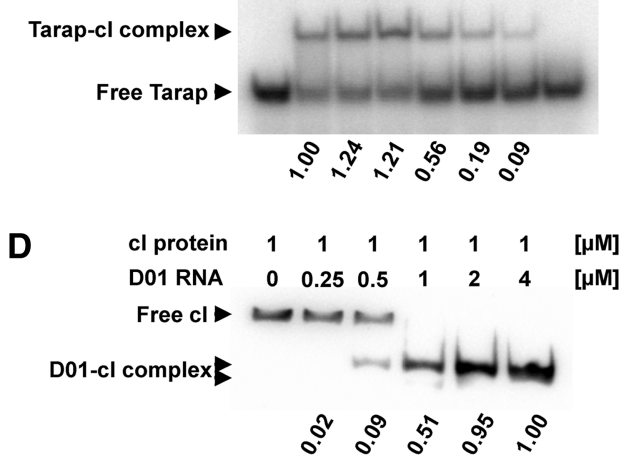

E

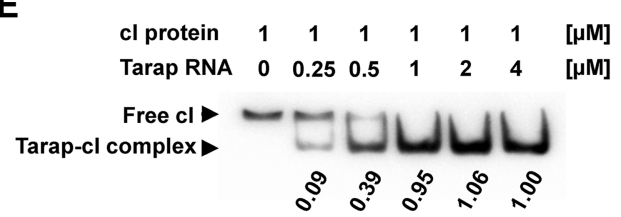

FIGURE 3. EMSA analyses of stoichiometry of the aptamer-cI complexes. (A) EMSA analysis of aptamer-cI complexes. Ten nanomoles of ${ }^{32} \mathrm{P}$-labeled aptamer (D01 or Tarap) RNA was incubated in the presence $(1 \mu \mathrm{M})$ or absence of $\mathrm{cI}$ protein at $37^{\circ} \mathrm{C}$ for $30 \mathrm{~min}$, and subjected to $6 \%$ PAGE. $(B, C)$ Titration analysis of complex formation of aptamers. Ten nanomoles of ${ }^{32} \mathrm{P}$-labeled aptamer D01 $(B)$ or aptamer Tarap $(C)$ was incubated in the presence $1 \mu \mathrm{M}$ cI protein and indicated concentrations of unlabeled aptamer D01 $(B)$ or aptamer Tarap $(C)$ at $37^{\circ} \mathrm{C}$ for $30 \mathrm{~min}$, and subjected to $6 \%$ PAGE. The relative band intensities of the complexes compared to the intensity in the absence of unlabeled aptamer are shown below the gel images. $(D, E)$ Titration analysis of the complex formation of cI protein. One $\mu \mathrm{M}$ hexa-histidine-tagged cI protein was incubated with indicated concentrations of aptamer D01 $(D)$ or aptamer Tapap $(E)$ at $37^{\circ} \mathrm{C}$ for $30 \mathrm{~min}$, and subjected to $6 \%$ PAGE. The bands of the cI protein were detected by western blotting using antihistidine tag antibody. The relative band intensities of the complexes compared to the intensity in the presence of $4 \mu \mathrm{M}$ cI protein are shown below the gel images.

(like the DNA-binding region) but other regions of the protein also. The mutations in aptamer Tarap may rearrange the orientation of these RNA loops, resulting in simultaneous recognition of the binding region of one protein molecule and the other region(s) of the other protein molecule in the cI dimer.

In the previous studies, dimeric aptamers were designed to generate agonists that promote receptor dimerization and signal induction (Dollins et al. 2008; McNamara et al. 2008; Ramaswamy et al. 2015; Ueki et al. 2016). The stoichiometry alteration by mutation of aptamers reported in this study may be applied for the generation of agonistic aptamers. Generating agonistic aptamers without sequence elongation would be effective when avoiding the risk of innate immunity response (Avci-Adali et al. 2013, 2015).

\section{MATERIALS AND METHODS}

\section{Preparation of recombinant hexa-histidine-tagged cl}

The recombinant cI protein was expressed in Escherichia coli BL21 (DE3) pLysS (Promega) cells harboring an over-expression plasmid, pET17b-cI, as previously described (Stayrook et al. 2008). The protein was purified from the crude cell lysate using HisTrap HP Resin (GE Healthcare), followed by dialysis against phosphate buffered saline $\left(8.1 \mathrm{mM} \mathrm{Na}_{2} \mathrm{HPO}_{4}, 1.47 \mathrm{mM} \mathrm{KH}_{2} \mathrm{PO}_{4}, 2.7 \mathrm{mM} \mathrm{KCl}, 137 \mathrm{mM}\right.$ $\mathrm{NaCl}[\mathrm{pH} 7.4]$ ) supplemented with $1 \mathrm{mM}$ DTT at $4^{\circ} \mathrm{C}$ overnight. Then, glycerol (final concentration 50\%) was added to the dialyzed sample, and the sample was stored at $-20^{\circ} \mathrm{C}$ until use.

\section{Identification of active mutations of aptamer D01}

Two rounds of SELEX against recombinant hexa-histidine-tagged cI were performed as previously described (Ohuchi 2014; Ohuchi and Suess 2017). As a template for the initial pool, the following synthetic DNA was used: $5^{\prime}$-TAATACGACT CACTATAGGG CTGAAGG ATG CCATTTTTTT CTAGAgggat cgacagggct cccgattggc tcggcgaaga tcgcctgtac tgtggaaagc cgagtcgtgC CATCTAGATC TCCACCG-3' (T7 promoter and restriction sites are indicated by italics and underlining, respectively. Of note, $15 \%$-doped region is indicated with lowercase letters). All synthetic DNAs were purchased from Sigma-Aldrich Chimie. In the first round, $100 \mathrm{pmol}$ of cI protein and $5 \mu \mathrm{L}$ of MagneHis resin (Promega) were used. After the RNA binding, the resin was washed with the selection buffer four times. In the second round, $50 \mathrm{pmol}$ of $\mathrm{cI}$ protein and $2.5 \mu \mathrm{L}$ of MagneHis resin were used, and the washing was performed 10 times. The Round 2 pool was then subjected to in vivo screening based on the blue-white colony color assay as described previously (Ohuchi and Suess 2017).

\section{Miller assay}

The in vivo transcriptional activator activity was quantitatively analyzed by the Miller assay as previously described (Hunsicker et al. 2009; Ohuchi and Suess 2017).

\section{Filter-retardation assay}

Affinity of aptamer Tarap was analyzed by a filter-retardation assay as previously described (Hunsicker et al. 2009; Ohuchi and Suess 2017). 


\section{Northern blotting}

Aptamer expression amounts were analyzed by northern blotting as previously described (Vockenhuber et al. 2015). The RNA samples were prepared using TRIzol reagent (Invitrogen/ThermoFisher Scientific) from cells harvested at the late stationary phase. The following synthetic DNAs were used as probes for the detection of aptamer RNAs and 5S RNA: 5'-TGTCGATCCC TCTAGAGGGA AACGTTG-3' (5'-region of aptamers); 5'-GGCCCCAAGG GGTT ATGCTA AGATCT-3' (3'-region of aptamers); 5'-CGGCGCTA CG GCGTTTCACT TCTG-3' (5S RNA). The band images were analyzed by FLA-5000 (Fuji Film).

\section{Electrophoretic mobility shift assay (EMSA)}

EMSA was performed as previously described (Ohuchi 2014). Trace amount (final concentration $10 \mathrm{nM}$ ) of ${ }^{32} \mathrm{P}$-labeled aptamer and indicated concentrations of unlabeled aptamer were folded as previously described (Ohuchi 2014; Ohuchi and Suess 2017) and mixed with cI protein $(1 \mu \mathrm{M})$. After 30 -min incubation at $37^{\circ} \mathrm{C}$, the mixture was quickly chilled on ice, and glycerol (final concentration $10 \%$ ) was added. The mixture was subjected to polyacrylamide gel electrophoresis (PAGE) using a $6 \%$ gel in $1 \times$ TBE (Tris-borateEDTA) buffer supplemented with $3 \mathrm{mM} \mathrm{MgCl}_{2}$. The electrophoresis was performed at $100 \mathrm{~V}$ for $1 \mathrm{~h}$ at $4^{\circ} \mathrm{C}$. The band images were analyzed by FLA- 5000 .

For EMSA analysis of mobility shift of cI protein, sample preparation, and PAGE were performed as described above in the absence of ${ }^{32} \mathrm{P}$-labeled aptamer. After the electrophoresis, the gel was soaked in Tris-glycine-SDS buffer ( $25 \mathrm{mM}$ Tris- $\mathrm{HCl}, 192 \mathrm{mM}$ glycine, $0.1 \%$ sodium dodecyl sulphate, $\mathrm{pH} 8.3$ ) at room temperature for $3 \mathrm{~min}$. The protein bands were transferred onto Amersham Protran NC Nitrocellulose Membranes (GE Healthcare). Immunodetection was performed using Invitrogen $6 \times$ His Epitope Tag Antibody (ThermoFisher Scientific), Peroxidase AffiniPure Rabbit AntiMouse IgG (Jackson ImmunoResearch), and ECL Western Blotting Detection Reagents (GE Healthcare) as primary antibody, secondary antibody, and chemiluminescent horseradish peroxidase substrate, respectively. The band images were analyzed by ChemiDoc MP Imaging System (Bio-Rad).

\section{SUPPLEMENTAL MATERIAL}

Supplemental material is available for this article.

\section{ACKNOWLEDGMENTS}

This work was supported by the Deutsche Forschungsgemeinschaft: SFB902 (A2) and the LOEWE Schwerpunkt CompuGene.

Received August 17, 2017; accepted December 21, 2017.

\section{REFERENCES}

Avci-Adali M, Steinle H, Michel T, Schlensak C, Wendel HP. 2013. Potential capacity of aptamers to trigger immune activation in human blood. PLoS One 8: e68810.
Avci-Adali M, Hann L, Michel T, Steinle H, Stoppelkamp S, Stang K, Narita M, Schlensak C, Wendel HP. 2015. In vitro test system for evaluation of immune activation potential of new single-stranded DNA-based therapeutics. Drug Test Anal 7: 300-308.

Biesecker G, Dihel L, Enney K, Bendele RA. 1999. Derivation of RNA aptamer inhibitors of human complement C5. Immunopharmacology 42: 219-230.

Dollins CM, Nair S, Boczkowski D, Lee J, Layzer JM, Gilboa E, Sullenger BA. 2008. Assembling OX40 aptamers on a molecular scaffold to create a receptor-activating aptamer. Chem Biol 15: 675-682.

Duclair S, Gautam A, Ellington A, Prasad VR. 2015. High-affinity RNA aptamers against the HIV-1 protease inhibit both in vitro protease activity and late events of viral replication. Mol Ther Nucleic Acids 4: e228.

Ellington AD, Szostak JW. 1990. In vitro selection of RNA molecules that bind specific ligands. Nature 346: 818-822.

Ellington AD, Chen X, Robertson M, Syrett A. 2009. Evolutionary origins and directed evolution of RNA. Int J Biochem Cell Biol 41: $254-265$.

Huang DB, Vu D, Cassiday LA, Zimmerman JM, Maher LJ III, Ghosh G. 2003. Crystal structure of NF-kB (p50) $)_{2}$ complexed to a high-affinity RNA aptamer. Proc Natl Acad Sci 100: 9268-9273.

Hunsicker A, Steber M, Mayer G, Meitert J, Klotzsche M, Blind M, Hillen W, Berens C, Suess B. 2009. An RNA aptamer that induces transcription. Chem Biol 16: 173-180.

Joyce GF. 2007. Forty years of in vitro evolution. Angew Chem Int Ed Engl 46: 6420-6436.

Kettenberger H, Eisenführ A, Brueckner F, Theis M, Famulok M, Cramer P. 2006. Structure of an RNA polymerase II-RNA inhibitor complex elucidates transcription regulation by noncoding RNAs. Nat Struct Mol Biol 13: 44-48.

McNamara JO, Kolonias D, Pastor F, Mittler RS, Chen L, Giangrande PH, Sullenger B, Gilboa E. 2008. Multivalent 4-1BB binding aptamers costimulate $\mathrm{CD}^{+} \mathrm{T}$ cells and inhibit tumor growth in mice. J Clin Invest 118: 376-386.

Miller MT, Tuske S, Das K, DeStefano JJ, Arnold E. 2016. Structure of HIV-1 reverse transcriptase bound to a novel 38-mer hairpin template-primer DNA aptamer. Protein Sci 25: 46-55.

Ohuchi S. 2014. Identification of RNA aptamers against recombinant proteins with a hexa-histidine tag. Methods Mol Biol 1111: 41-56.

Ohuchi S, Suess B. 2017. An inhibitory RNA aptamer against the lambda cI repressor shows transcriptional activator activity in vivo. FEBS Lett 591: 1429-1436.

Ohuchi S, Mori Y, Nakamura Y. 2012. Evolution of an inhibitory RNA aptamer against T7 RNA polymerase. FEBS Open Bio 2: 203-207.

Parashar A. 2016. Aptamers in therapeutics. J Clin Diagn Res 10: BE01-BE06.

Ramaswamy V, Monsalve A, Sautina L, Segal MS, Dobson J, Allen JB. 2015. DNA aptamer assembly as a vascular endothelial growth factor receptor agonist. Nucleic Acid Ther 25: 227-234.

Stayrook S, Jaru-Ampornpan P, Ni J, Hochschild A, Lewis M. 2008. Crystal structure of the $\lambda$ repressor and a model for pairwise cooperative operator binding. Nature 452: 1022-1025.

Tabarzad M, Jafari M. 2016. Trends in the design and development of specific aptamers against peptides and proteins. Protein $J$ 35: 81-99.

Tuerk C, Gold L. 1990. Systematic evolution of ligands by exponential enrichment: RNA ligands to bacteriophage T4 DNA polymerase. Science 249: 505-510.

Ueki R, Ueki A, Kanda N, Sando S. 2016. Oligonucleotide-based mimetics of hepatocyte growth factor. Angew Chem Int Ed 55: 579-582.

Vockenhuber MP, Heueis N, Suess B. 2015. Identification of metE as a second target of the sRNA scr5239 in Streptomyces coelicolor. PLoS One 10: e0120147. 

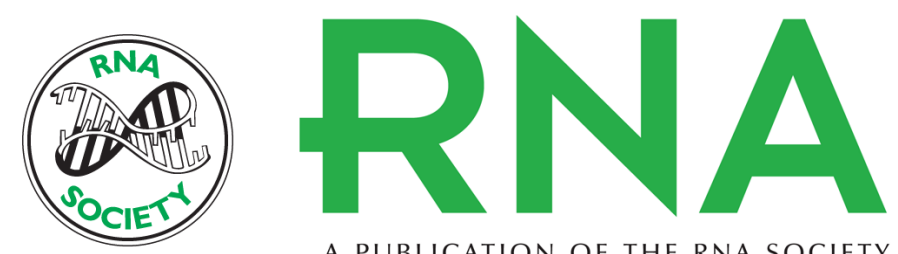

A PUBLICATION OF THE RNA SOCIETY

\section{Altered stoichiometry of an evolved RNA aptamer}

Shoji Ohuchi and Beatrix Suess

RNA 2018 24: 480-485 originally published online December 28, 2017

Access the most recent version at doi:10.1261/rna.063610.117

Supplemental Material

References

Creative Commons License

Email Alerting Service
http://rnajournal.cshlp.org/content/suppl/2017/12/28/rna.063610.117.DC1

This article cites 23 articles, 2 of which can be accessed free at: http://rnajournal.cshlp.org/content/24/4/480.full.html\#ref-list-1

This article is distributed exclusively by the RNA Society for the first 12 months after the full-issue publication date (see http://rnajournal.cshlp.org/site/misc/terms.xhtml). After 12 months, it is available under a Creative Commons License (Attribution-NonCommercial 4.0 International), as described at http://creativecommons.org/licenses/by-nc/4.0/.

Receive free email alerts when new articles cite this article - sign up in the box at the top right corner of the article or click here.

To subscribe to $R N A$ go to:

http://rnajournal.cshlp.org/subscriptions

(C) 2018 Ohuchi and Suess; Published by Cold Spring Harbor Laboratory Press for the RNA Society 